\title{
Identification and induction of cytochrome P450s involved in the metabolism of flavone-8-acetic acid in mice
}

Minh Hien Pham 1 , Hervé Rhinn 1 , Nicolas Auzeil 2 , Anne Regazzetti 2 , Djamel Eddine Harami 1 , Daniel Scherman 1 , Guy G. Chabot 1*

1 Unité de pharmacologie chimique et génétique et d'imagerie INSERM : U1022, CNRS : UMR8151, Université Paris V - Paris Descartes , Ecole Nationale Supérieure de Chimie de Paris , Paris,FR

2 Laboratoire de Chimie et Toxicologie Analytique et Cellulaire Université Paris V - Paris Descartes : EA4463 , Faculté des Sciences Pharmaceutiques et Biologiques, Paris, F-75006,FR

* Correspondence should be adressed to: Guy Chabot <guy.chabot@parisdescartes.fr >

\begin{abstract}
The metabolism of flavone-8-acetic acid (FAA) has been hypothesized to be partly responsible for its potent anticancer activity in mice. The purpose of this study was to identify the mouse enzymes involved in FAA Phase I metabolism and evaluate their possible induction in vivo by FAA. Mouse microsomes metabolized FAA into 6 metabolites: 3',4'-dihydrodiol-FAA, 5,6-epoxy-FAA, 4' -OH-FAA, 3'-OH-FAA, 3',4'-epoxy-FAA and 6-OH-FAA. Using Cyp-specific inhibitors (furafylline, Cyp1a2; $\alpha$-naphthoflavone, Cyp1b1; tranylcypromine, Cyp2b9; quercetin, Cyp2c29; quinidine, 2d9; diethyldithiocarbamate, Cyp2e1; ketoconazole, Cyp3a11),

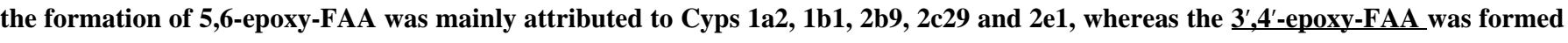
by Cyps 2b9 and 3a11. The 4'-OH-FAA was generated by Cyps 1a2, 1b1, 2 b9 and 2e1, and the 6-OH-FAA was formed by Cyps 1b1 and 2c9. Using the epoxide scavenger $\mathrm{N}$-acetyl cysteine, 4'-OH-FAA, 3'-OH-FAA and 6-OH-FAA were shown to derive partly from non enzymatic isomerisation of their corresponding epoxides. The specific epoxide hydrolase inhibitor elaidamide allowed the confirmation that $3^{\prime}, 4^{\prime}$-dihydrodiol-FAA was formed via the epoxide hydrolase. FAA treatment in vivo in mice led to a significant increase in the hepatic expression of Cyp1a2 (1.9-fold), 2e1 (2.1-fold), 2 b10 (3.2-fold), 2 d9 (2.3-fold) and 3a11 (2.2-fold), as evaluated by qRT-PCR. In conclusion, several Cyps were shown to be involved in FAA metabolism, particularly Cyps 3a11 and $2 \mathrm{b9}$ which were responsible for the formation of the principal metabolites (5,6-epoxy-FAA, $3^{\prime}, 4^{\prime}$-epoxy-FAA), and that FAA could induce the expression of several Cyps after in vivo administration. The possible implication of these enzymes in the in vivo anticancer activity of FAA in mice is discussed.
\end{abstract}

MESH Keywords Acetylcysteine ; metabolism ; Animals ; Cytochrome P-450 Enzyme System ; physiology ; Enzyme Induction ; Epoxide Hydrolases ; physiology ; Female ; Flavonoids ; metabolism ; Hydroxylation ; Mice ; Mice, Inbred C57BL ; Microsomes, Liver ; metabolism

\section{INTRODUCTION}

The flavonoids are natural compounds possessing a large range of biochemical and pharmacological properties [1] including antitumoral activities [2]. Among the flavonoids identified as potential anticancer agents, flavone-8-acetic acid (FAA; 2-phenyl-8-(carboxymethyl)benzopyran-4-one; NSC-347512; LM975; Figure 1-A) emerged as an interesting lead because of its potent anticancer activity in mouse solid tumors [3-6] and also in human tumors transplanted in nude mice [7;8]. However, despite its impressive antitumor activity reported in murine models, FAA has not shown anticancer activity in humans [9;10]. This marked interspecies difference in FAA anticancer activity has been hypothesized to be due to a possible metabolic activation of this flavonoid in vivo in mice [11;12].

The mechanism of anticancer activity of FAA in mice is not fully elucidated. FAA is weakly cytotoxic in vitro but is active in vivo when the same cell lines are transplanted in mice [12-14]. In view of this discrepancy between in vivo and in vitro effectiveness, several indirect mechanisms of anticancer action have therefore been suggested: augmentation of natural killer activity and induction of interferon [15]; antiangiogenic properties [16]; tumor blood flow shut down and induction of extensive hemorrhagic necrosis [3;17-20]. At the molecular level, FAA has been reported to induce DNA damage in Glasgow osteogenic sarcoma after in vivo administration, which could hint to an in vivo formation of reactive metabolites in mice [21].

In view of the poor cytotoxic activity of FAA in vitro and its potent anticancer activity in vivo in mice, the requirement for FAA metabolic activation has therefore been hypothesized [11;12]. In a search for potentially active FAA metabolites, we have previously identified six FAA phase I metabolites formed in vitro using mouse microsomes [22]. The identified metabolites include three monohydroxylated derivatives (3'-OH-FAA, 4'-OH-FAA and 6-OH-FAA), two epoxides (3',4'-epoxy-FAA and 5,6-epoxy-FAA), and one dihydrodiol (3',4'-dihydodiol-FAA) (Figure 1-A) [22]. We have also shown that human microsomes were unable to metabolize this compound to a significant extent, as compared with mouse microsomes [22]. Although the mouse genome contains 72 putatively functional CYP genes compared to only 27 in humans [23], the cytochrome P450s (CYP) sub-families mostly involved in drug metabolism, i.e., the CYP1A, CYP2B, CYP2E, CYP3A and CYP4A appear to be roughly similar between mouse and man, although differences are observed in activity and also in inhibition studies [24;25]. 
Although mouse microsomes were shown to metabolize FAA, the enzymes responsible for their production are not presently identified. The purpose of the present study was therefore to identify the mouse enzymes involved in the formation of the principal FAA metabolites. The identification of the various mouse cytochrome P450s (Cyps, in lower case for mice) was accomplished using Cyp-specific inhibitors, and the implication of epoxide hydrolase was tested using elaidamide, a specific epoxide hydrolase inhibitor. In addition, because flavonoids have been shown to influence the expression of several Cyps after in vivo administration [26], the influence of FAA treatment in mice on the expression of the principal hepatic Cyps was also investigated using quantitative RT-PCR. We have found that different sets of Cyps are involved in the formation of specific FAA metabolites and that FAA was shown to induce several hepatic Cyps after in vivo administration in mice.

\section{MATERIALS AND METHODS}

\section{Chemicals}

Flavone-8-acetic acid (FAA, LM975, NSC347512, Fig. 1-A) and FAA mono-hydroxylated products at position 3' or 4' were kindly provided by Dr Jean-Jacques Berthelon (Merck-Lipha Santé, Lyon, France). The 6-OH-FAA was synthesized as previously described [22] using appropriate starting material [27-29]. The 3',4'-dihydrodiol-FAA, the 3',4'-epoxy-FAA and the 5,6-epoxy-FAA were generated in vitro using aroclor 1254 induced mouse microsomes according to the protocol described below. The following Cyp inhibitors were purchased from Sigma-Aldrich: furafylline (Cyp1a2), a-naphthoflavone (Cyp1b1), tranylcypromine (Cyp2c29, Cyp2c39), quercetin (Cyp2c29), quinidine (Cyp2d9), diethyldithiocarbamate (Cyp2e1) and ketoconazole (Cyp3a11). The specific epoxide hydrolase inhibitor elaidamide was synthesized and kindly provided by Dr Christophe Morisseau [30]. Aroclor 1254 was obtained from Sigma-Aldrich (Saint Quentin Fallavier, France). All other chemicals were obtained from commercial suppliers and were of the highest purity available.

\section{Preparation of aroclor-induced mouse microsomes}

Aroclor-induced mouse microsomes were prepared according to the protocol described by Breinholt et al. [31]. Female C57Bl/6 mice, 8 weeks of age were purchased from Janvier (Le Genest-St-Isle, France) and acclimated for a week in our animal facility and kept on a 12 $\mathrm{h}$ light/dark cycle with free access to food. Mice were injected intraperitoneally with aroclor-1254 (500 mg/kg body weight) dissolved in corn oil on day 0 , and 5 days later the mice were sacrificed by cervical dislocation after a $24 \mathrm{~h}$ fasting period. All animal experiments complied with the French regulations concerning the protection of animals used for experimental and other scientific purposes (D2001-486), and with the European Commission regulations (OJ of ECL358 12/18/1986). The hepatic microsomes were prepared as described by Guengerich [32]. Briefly, the livers were immediately excised and rinsed in ice-cold $\mathrm{KCl} 1.15 \%$ solution, pooled and cut into small pieces with scissors. Four volumes of $0.1 \mathrm{M}$ phosphate buffer $(\mathrm{pH}$ 7.4) were added and the livers homogenized using a Teflon potter at a speed of $50 \mathrm{rpm}$ with 10 strokes. The liver homogenate was centrifuged at 15,000 $\times \mathrm{g}$ for 20 min. After lipid elimination, the supernatant was ultra-centrifuged at $100,000 \times \mathrm{g}$ during $60 \mathrm{~min}$, at $4^{\circ} \mathrm{C}$. The pellet containing the microsomes were collected, covered by a phosphate buffer containing $20 \%$ glycerol, snap frozen on dry ice, and stored at $-80^{\circ} \mathrm{C}$ until use. Total microsomal protein was determined using the Pierce BCA Protein Assay Reagent Kit (Rockford, IL, USA).

\section{In vitro metabolism of FAA}

Metabolism of FAA was carried out according to our previously described protocol [22]. In brief, FAA (8 $\mu \mathrm{g} / \mathrm{ml}$ final concentration) was incubated in $300 \mu \mathrm{l}$ TRIS-HCL $0.1 \mathrm{M}$ buffer, $\mathrm{pH} 7.4$, containing $0.5 \mathrm{mg} / \mathrm{ml}$ microsomal protein, $1.6 \mathrm{mg} / \mathrm{ml} \mathrm{BSA,} 5 \mathrm{mM} \mathrm{MgCl}$ and a NADPH generating system corresponding to $1.3 \mathrm{mM}$. The incubation was carried out in opened $2 \mathrm{ml}$ polypropylene tubes in a shaking water bath $(150$ oscillations $/ \mathrm{min})$ at $37^{\circ} \mathrm{C}$. The reaction mixture was pre-warmed at $37^{\circ} \mathrm{C}$ for 3 min before the NADPH generating system was added and the incubation time was extended for an additional $60 \mathrm{~min}$. The generation of metabolites was linear with time up to $2 \mathrm{~h}$ and protein concentration up to $2 \mathrm{mg} / \mathrm{ml}$ of microsomal protein, therefore the conditions used in the inhibition experiments ( $1 \mathrm{~h}$ and 0.5 $\mathrm{mg} / \mathrm{ml}$ protein) were within the linear range. The incubation mixture was extracted twice with $800 \mu \mathrm{l}$ ethyl acetate containing $2 \%$ acetic acid (v/v), the organic phase was evaporated under nitrogen and kept in dry form at $-80^{\circ} \mathrm{C}$, and then reconstituted with $300 \mu \mathrm{l}$ of the HPLC mobile phase immediately prior HPLC analysis. One hundred $\mu \mathrm{l}$ of the reconstituted residue were injected onto the Shimadzu HPLC system. In these incubation conditions, mouse aroclor-induced microsomes could metabolize $4.3 \pm 0.3 \%$ of the FAA.

\section{Determination of mouse Cyp enzymes involved in the FAA metabolism in vitro}

To determine mouse Cyps involved in the FAA metabolism, FAA metabolism by aroclor-induced mouse microsomes in vitro was carried out in absence or presence of various concentrations of specific Cyp inhibitors. The mouse Cyp orthologs corresponding to their human CYP counterparts are as follows [23]: Cyp1a2, CYP1A2; Cyp1b1, CYP1B1; Cyp2b9, CYP2B6; Cyp2c39, CYP2C19; Cyp2d9, CYP2D6; Cyp2e1, CYP2E1; Cyp3a11, CYP3A4. The specific Cyp inhibitors used were: furafylline (Cyp1a2), a-naphthoflavone (Cyp1b1) [33], tranylcypromine (Cyp2c29), quinidine (Cyp2d9) [34], diethyldithiocarbamate (Cyp2e) [35] and ketoconazole (Cyp3a11) [36 ]. Furafylline, a-naphthoflavone and ketoconazole were dissolved in DMSO, quercetin was dissolved in methanol, and tranylcypromine, quinidine, and diethyldithiocarbamate were dissolved in Tris- $\mathrm{HCl}$ buffer. Appropriate controls were run for the solvents which did not 
exceed $2 \%$ in volume in the control tube and in the test tube. The choice of inhibitors range concentrations were based on Bogaards et al. [ 24] (and references therein). The inhibitors were added to the incubation mixture containing microsomes 10 min before the addition of the NADPH generating system. The incubation and extraction conditions were carried out as described above for aroclor-induced mouse microsomes.

\section{Epoxide hydrolase inhibition}

Because the 3',4'-dihydrodiol-FAA was likely generated from the hydolysis of the 3',4'-epoxy-FAA by the epoxide hydrolase, we determined the role of this enzyme using elaidamide, an epoxide hydrolase inhibitor [30], at final concentrations of 2,4 and $10 \mu \mathrm{M}$.

\section{Non-enzymatic transformations}

Non-enzymatic transformations during FAA metabolism incubation were determined by analysis of transformation of FAA metabolites in PBS buffer. FAA metabolites extract was reconstituted in $300 \mu \mathrm{PBS}$ buffer incubated at $37^{\circ} \mathrm{C}$ in a shaking water bath and injected onto the Shimadzu HPLC system at time 0 and 60 min.

\section{Evaluation of direct or indirect hydroxylation}

In order to determine if FAA monohydroxylates were formed directly from FAA or indirect via epoxidation (Guengerich et al., 2003), FAA metabolism by aroclor-1254 induced mouse microsomes was carried out in presence of the epoxide scanvenger $\mathrm{N}$-acetyl cysteine (NAC) according to the protocol described by Bu et al. [37]. In brief, NAC was added to the the pre-warmed incubation mixture at a final concentration of 7.5 mM. FAA metabolites and NAC adducts were further analyzed on the LC/MS systems described below.

\section{HPLC-UV and HPLC-UV-MS conditions}

Two HPLC systems were used during this project. The first, HPLC-UV system was a Shimadzu CLASS-VP ${ }^{\circledR}$ (version 5.3), equipped with a $\mathrm{C}_{18}$ column (Beckman Ultrasphere ODS, $5 \mu \mathrm{m} ; 4.6 \times 25 \mathrm{~mm}$ ) thermostated at $20^{\circ} \mathrm{C}$, and a UV detector set at $300 \mathrm{~nm}$. The mobile phase consisted of a solution of $26 \%$ methanol, $19 \%$ acetonitrile, $55 \%$ aqueous acetic acid (2\%), at a flow rate of $1 \mathrm{ml} / \mathrm{min}$. The second system of LC-MS/MS consisted of a Surveyor ${ }^{\circledR}$ HPLC equipped with a UV diode array detector and was coupled with a mass spectrometer (LCQ-Advantage ${ }^{\circledR}$, ThermoElectron). The mass spectrometer consisted of an electrospray ionization system used in positive ion polarity mode and a quadrupole ion trap mass analyzer. The operating parameters where as follows: the spray needle voltage was set at $4.0 \mathrm{kV}$ and the spray was desolvated with a nitrogen sheath gas. Electrospray capillary voltage was $4.0 \mathrm{~V}$, nitrogen was used as auxilliary gas and the capillary temperature was $250^{\circ} \mathrm{C}$. A C 18 reversed phase column (EC. 250/2 Nucleodur Sphinx RP, $5 \mu \mathrm{m}, 250 \mathrm{~mm} \mathrm{X} 2.1 \mathrm{~mm}$, Macherey-Nagel) thermostated at $30^{\circ} \mathrm{C}$ was used. The metabolites were resolved using the following tertiary gradient: from 0 to 25 min: 7 -24\% methanol; 4-13\% acetonitrile; 89-63 \% TFA $0.1 \%$. From 25 to 40 min: 24-26 \% methanol; $13-14 \%$ acetonitrile; 63-60 \% TFA 0.1 \%. From 40 to 42 min: 26-45\% methanol; 14-22\% acetonitrile; 60-33\% TFA 0.1\%. From 42 to 47 min: $45 \%$ methanol; $22 \%$ acetonitrile; 33 \% TFA $0.1 \%$. From 47 to 49 min: $45-7 \%$ methanol; $22-4 \%$ acetonitrile; $33-89 \%$ TFA $0.1 \%$. And, finally from 49 to 75 min: $7 \%$ methanol; $4 \%$ acetonitrile; $89 \%$ TFA $0.1 \%$. Flow rate was $0.2 \mathrm{ml} / \mathrm{min}$. Volume of injection was $50 \mu \mathrm{l}$. The Xcalibur ${ }^{\circledR}$ software was used for data acquisition and analysis.

\section{In vivo treatment with standard Cyp inducers and FAA}

Female C57Bl/6 mice, 8 weeks of age were purchased from Janvier (Le Genest-St-Isle, France) and acclimated for a week in our animal facility and kept on a $12 \mathrm{~h}$ light/dark cycle with free access to food. The mice were injected i.p. (intraperitoneally) in a volume of $0.2 \mathrm{ml}$ with the following inducers at the indicated doses and schedules (five mice per group): Control A mice received $0.9 \%$ saline i.p. for 3 consecutive days; Control B mice received corn oil i.p. on 3 consecutive days; 3-Methylcholanthrene, $80 \mathrm{mg} / \mathrm{kg}$, i.p., suspended in corn oil was administered for 3 consecutive days (Monday, Tuesday, Wednesday) [38], $\beta$-naphthoflavone, $80 \mathrm{mg} / \mathrm{kg} / \mathrm{day}$, i.p., suspended in corn oil, for 3 consecutive days [39]; Dexamethasone, $100 \mathrm{mg} / \mathrm{kg} / \mathrm{day}$, i.p., suspended in corn oil, for 3 consecutive days [39]; for all the previous treatments, the mice were sacrificed on the fifth day after an overnight fasting. Aroclor 1254 (500 mg/kg, dissolved in corn oil) was administered on day 1 , and the mice were sacrificed on the 5th day after an overnight fasting [31]. Phenobarbital was administered in drinking water $(0.1 \%)$ for 10 days, and the mice were sacrificed on the 11 th day after an overnight fasting. For FAA, two treatment schedules were tested: FAA treatment A, consisted of one i.p. one dose on day $1(180 \mathrm{mg} / \mathrm{kg})$, and the mice were sacrificed on day 5 after an overnight fasting [3;4] FAA treatment B included 3 i.p. administration (at $180 \mathrm{mg} / \mathrm{kg}$ each) on days 1, 3 and day 5, and the mice were sacrificed on day 9 after an overnight fasting [3;4]. Immediately upon sacrificing the mice $\left(\mathrm{CO}_{2}\right)$, the liver was quickly removed, rinsed with ice cold PBS, and aliquots of each liver lobe were immediately transferred to a tube containing a RNAlater solution (QIAGEN) and were kept at $4^{\circ} \mathrm{C}$ for further extraction of total RNA.

\section{Quantitative RT-PCR}


Extraction of total RNA was accomplished using RNable (Eurobio), and one microgram of total RNA, as measured with Ribogreen measurement, was reverse transcribed in a final volume of $20 \mu \mathrm{l}$ containing $4 \mu \mathrm{L}$ of 5 X RT buffer, 20 units of RNasin RNase inhibitor (Promega), $10 \mathrm{mM}$ DDT, 100 units of Superscript II RNase H- reverse transcriptase (Invitrogen), and 3 mM random hexamers (Invitrogen). The samples were incubated at $20^{\circ} \mathrm{C}$ for $10 \mathrm{~min}, 42{ }^{\circ} \mathrm{C}$ for $30 \mathrm{~min}$, and $99^{\circ} \mathrm{C}$ for $5 \mathrm{~min}$. Real-time PCR reactions were carried out using ABI PRISM 7900HT Sequence Detection System (Applied Biosystems) in a 384-well, clear optical reaction plate with optical adhesive covers (Applied Biosystems). The PCR primers for the genes of interest were designed with the Oligo6 software using the GenBank reference sequences (Table 1). They were chosen in such a manner to be in distinct exons, to ensure a specific cDNA versus genomic DNA amplification, and their specificity was assessed using the NCBI BLAST website. Reactions were run in a $5 \mu$ volume in duplicate, with $2 \mu \mathrm{L}$ of cDNA solution, $2.5 \mu \mathrm{L}$ of Power SYBR Green Master Mix (Applied Biosystems) and $0.5 \mu \mathrm{L}$ of $10 \mu \mathrm{M}$ primers solution. The PCR program was: $95^{\circ} \mathrm{C}$ for $10 \mathrm{~min}$, followed by 45 cycles of $\left(15\right.$ seconds at $95^{\circ} \mathrm{C} ; 1 \mathrm{~min}$ at $\left.60^{\circ} \mathrm{C}\right)$. Cycle threshold values were obtained from the ABI PRISM 7900 SDS software. For each PCR well, raw fluorescence data were exported and a curve-fitting method was applied to evaluate the individual efficiencies [40]. For each target the efficiency was considered as shared for all wells. This efficiency was set as the mean of the fitted individual efficiencies. Individual Ct values exported from the SDS software were used to

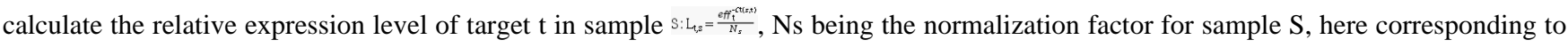
the total cDNA level as measured with Oligreen. Oligreen fluorescence measurements were carried out using the ABI PRISM 7900HT Sequence Detection System. Reactions were run in a $10 \mu \mathrm{l}$ volume in triplicate, with $5 \mu \mathrm{L}$ of cDNA solution and $5 \mu \mathrm{L}$ of Oligreen stock solution (Invitrogen) 200x diluted in TE buffer. Fluorescence was continuously read at $80^{\circ} \mathrm{C}$ for $30 \mathrm{sec}$, a condition which ensures exclusive cDNA measurement [41].

\section{RESULTS}

\section{FAA metabolism using aroclor-induced mouse microsomes}

Figure 1-A presents the structures of FAA metabolites formed by aroclor-induced mouse microsomes, and Figure 1-B depicts a typical HPLC-UV chromatogram of FAA and its major phase I metabolites. The parent compound FAA eluted at 17.1 min, whereas the six previously identified metabolites [22], that were all more hydrophilic than FAA, eluted at the following retention times in this reversed-phase HPLC system (Figure 1-B): 3',4'-dihydrodiol-FAA (Rt 4.1 min); 5,6-epoxy-FAA (Rt 7.6 min); 4'-OH-FAA (Rt 9.0 min); 3' -OH-FAA (Rt $10.0 \mathrm{~min}$ ); 3', $4^{\prime}$-epoxy-FAA (Rt $11.2 \mathrm{~min}$ ); and 6-OH-FAA (Rt $12.3 \mathrm{~min}$ ). Among these metabolites, the two FAA epoxides (5,6-epoxy-FAA and 3',4'-epoxy-FAA) were the predominant ones, representing $36.3 \pm 1.1 \%$ and $26.7 \pm 1.5 \%$ of the total metabolite area, respectively (as evaluated at $300 \mathrm{~nm}$ ). The 3',4'-dihydrodiol-FAA, the 4'-OH-FAA, the 3'-OH-FAA and the 6-OH-FAA, represented $14.0 \pm 0.6 \%, 6.8 \pm 0.6 \%, 1.6 \pm 0.6 \%$ and $14.5 \pm 1.0 \%(\mathrm{n}=3)$ of the total metabolite area, respectively.

\section{Mouse Cyp enzymes involved in FAA metabolism}

In order to identify the mouse Cyps involved in FAA metabolism, incubations were carried out in absence or presence of increasing concentrations of the Cyp-specific inhibitors presented in Table 2. The possible interference between FAA metabolites and inhibitors (or their possible metabolites) was also assessed by incubating the inhibitors alone with mouse microsomes.

Furafylline, a Cyp1a2 inhibitor, was tested in the concentration range of 5, 10, 20 and $50 \mu \mathrm{M}$. In absence of furafylline, all the above identified FAA metabolites were detected (Fig. 2-A). In presence of furafylline (Rt, $5.2 \mathrm{~min}$ ), which did not interfere with the elution profile of FAA metabolites (Fig. 2-B), all the FAA metabolites were reduced up to maximal values of 36 to $57 \%$ at the maximal inhibitor concentration used $(50 \mu \mathrm{M})$ (Table 2). However, because high inhibitor concentrations may lead to unspecific inhibition, the intermediate $10 \mu \mathrm{M}$ concentration appears as a better indicator of specific inhibition (above 20\%) for the formation of metabolites 5,6-epoxy-FAA and 4 '-OH-FAA.

The Cyp1b1 inhibitor $\alpha$-naphthoflavone was tested at final concentrations ranging from 5 to $20 \mu \mathrm{M}$ (Table 2). Most FAA metabolites were highly inhibited in presence of $\alpha$-naphthoflavone and the reduction of metabolite areas was also inhibitor concentration-dependent with values of 70 to $89 \%$ at the maximal concentration of inhibitor $(20 \mu \mathrm{M})$. Of interest, concerning the $3^{\prime}, 4^{\prime}$-epoxy-FAA, a biphasic effect was observed, as the low concentrations of the inhibitor $(5$ and $10 \mu \mathrm{M})$ led to an increase in the production of $3^{\prime}, 4^{\prime}$-epoxy-FAA, whereas higher concentrations produced a maximum inhibition of $40 \%$ (Table 2). As indicated above, because high concentrations of inhibitor may be involved in unspecific inhibition, it appears that at the intermediate concentration of $10 \mu \mathrm{M}$, the following metabolites were inhibited by more than 20\%: 3',4'-dihydrodiol-FAA; 5,6-epoxy-FAA; 4'-OH-FAA; and 6-OH-FAA.

The involvement of Cyp2b9 and Cyp2c39 was determined using the inhibitor tranylcypromine. All the metabolites achieved more that $40 \%$ inhibition at the the intermediate $50 \mu \mathrm{M}$ concentration of the inhibitor, with the exception of the 6-OH-FAA (Table 2).

Quercetin, a Cyp2c29 inhibitor, led to a 52\% inhibition of the 3',4'-dihydrodiol-FAA, a 73\% inhibition of the 5,6-epoxy-FAA and a 85 $\%$ inhibition of the 6-OH-FAA at the highest concentration tested of $30 \mu \mathrm{M}$ (Table 2). At the intermediate concentration of $20 \mu \mathrm{M}$, only 
5,6-epoxy-FAA and 6-OH-FAA were mostly inhibited with $48 \%$ and 53\% inhibition, respectively. The chromatographic interference of quercetin with the elution of 4'-OH-FAA and 3', 4'-epoxy-FAA in our HPLC conditions precluded the detection of these metabolites with this inhibitor. However, the indirect production of these metabolites via the measurable production of the $3^{\prime}, 4^{\prime}$-dihydrodiol-FAA, probably generated via the 3',4'-epoxy-FAA, is an indirect evidence of an inhibition of these B ring metabolites.

The involvement of Cyp2d9 was determined using quinidine as the inhibitor. Our results demonstrated that Cyp2d9 was not significantly involved in the formation of any metabolite even at a relatively high inhibitor concentration of $10 \mu \mathrm{M}$ which is twice the usual concentration employed for this inhibitor [24] (Table 2).

In presence of diethyldithiocarbamate, a Cyp2e1 inhibitor, the production of 5,6-epoxy-FAA and 4'-OH-FAA was significantly inhibited $(>20 \%)$ at an intermediate concentration of this inhibitor $(100 \mu \mathrm{M})($ Table 2$)$.

The contribution of Cyp3a11 to the production of FAA metabolites was determined with the specific inhibitor ketoconazole at final concentrations ranging from 2 to $40 \mu \mathrm{M}$. In presence of low $(2 \mu \mathrm{M})$ to moderate $(4 \mu \mathrm{M})$ concentrations of this inhibitor, only the $3^{\prime}, 4^{\prime}$ ,-dihydiol-FAA was highly inhibited by $75 \%$ and $88 \%$, respectively, indicating that Cyp3a11 was indeed involved in the formation of the 3 ,4,-epoxy-FAA intermediate metabolite (Table 2).

\section{Determination of direct or indirect monohydroxylation of FAA}

Because the monohydroxylated FAA metabolites could be derived from 2 metabolic routes, i.e., a direct hydroxylation or an hydroxylation via an epoxidic intermediate [42], we next evaluated the contribution of each pathway to their formation. The metabolism of FAA was conducted in absence or presence of the epoxide scavenger N-acetylcysteine (NAC). Because NAC adducts are very hydrophilic, we had to use gradient elution conditions in order to separate the adducts from the other metabolites as described in Materials and Methods.

In absence of NAC, FAA was metabolized by aroclor-induced mouse microsomes into several metabolites as shown in Figure 3-A. In these highly resolutive gradient elution conditions, FAA metabolites were eluted at the following retention times (Rt): $3^{\prime}, 4^{\prime}$ -dihydrodiol-FAA = $28.5 \mathrm{~min} ; 5$,6-epoxy-FAA = $39.7 \mathrm{~min} ; 4^{\prime}$-OH-FAA = $43.9 \mathrm{~min} ; 3^{\prime}$-OH-FAA = $45.6 \mathrm{~min} ; 3^{\prime}, 4^{\prime}$-epoxy-FAA = $47.4 \mathrm{~min}$; 6-OH-FAA = $49.1 \mathrm{~min}$; and, FAA = $56.6 \mathrm{~min}$ (Figure 3-A).

In presence of the scavenger NAC, all metabolite peaks were reduced (Figure 3-B). However, the 2 epoxides and the $3^{\prime}, 4^{\prime}$ -dihydrodiol-FAA peaks were more dramatically reduced compared to the other peaks (Figure 3-B). In parallel to the decrease of two epoxides, we also observed the formation of 4 new peaks at Rt of 26.4, 29.7, 30.2 and 31.5 min (Figure 3-B). Mass spectrum analysis of these 4 new peaks presented the same molecular ion $\mathrm{m} / \mathrm{z}, 460[\mathrm{M}+\mathrm{H}]^{+}$which corresponded to the molecular ion of conjugation of one FAA epoxide (MW 296) with a molecule of NAC (MW 163) (Figure 3-C).

To ascertain that the NAC adducts were produced directly with the two FAA epoxides, and not from FAA or its monohydroxylated metabolites, we performed control incubations of FAA with microsomes, but without NAC (Figure 3-D) which did not show any peak at $m / z, 460[\mathrm{M}+\mathrm{H}]^{+}$. In addition, control incubations with FAA and its monohydroxylated derivatives (i.e., 3'-, 4'-, and 6-OH-FAA) with NAC, but without microsomes, did not yield any molecular ion at $\mathrm{m} / \mathrm{z} 460$ (results not shown), indicating that epoxide formation is required for the appearance of $\mathrm{m} / \mathrm{z}$ peaks at 460 . Because the presence of NAC was also accompanied by a complete disappearance of $3^{\prime}, 4^{\prime}$ -dihydrodiol-FAA, it was therefore deduced that the latter was derived from its corresponding $33^{\prime}, 4^{\prime}$-epoxy-FAA.

As mentioned above, it was observed that in presence of NAC, the 4'-OH-FAA, the $3^{\prime}-\mathrm{OH}-\mathrm{FAA}$ and the 6-OH-FAA, were significantly reduced. The 4'-OH-FAA and the 3'-OH-FAA peaks were reduced by 86 and 67\%, respectively, whereas the 6-OH-FAA metabolite was diminished by $40 \%$ (Figure 3-B). However, because these peaks were not completely suppressed in presence of the scavenger NAC, this is an indication that direct oxidation of FAA to the monohydroxylated metabolites is also taking place.

\section{Non-enzymatic transformation of the epoxides to their corresponding monohydroxylated FAA derivatives}

Because the two FAA epoxides were found unstable and that they apparently were transformed into their corresponding mono-hydroxylated derivatives in the incubation conditions $\left(\mathrm{pH} 7.4,37^{\circ} \mathrm{C}\right)$, we next explored the possible contribution of their non-enzymatic transformations to their corresponding phenolic compounds. To do so, FAA metabolite extracts were reconstituted in PBS buffer and incubated at $37^{\circ} \mathrm{C}$ for $1 \mathrm{~h}$. We observed that the peak areas of the 5,6-epoxy-FAA decreased by $47 \%$, whereas the $3^{\prime}, 4^{\prime}$ -epoxy-FAA decreased by $15 \%$. In parallel, their corresponding phenols, i.e., the 6-OH-FAA peak was doubled (100 \% increase), the $4^{\prime}$ -OH-FAA was increased by $70 \%$, and the 3 -OH-FAA was increased by $171 \%$. It is of interest that the formation of the 5-OH-FAA was not observed in this experiment. It was also noteworthy that the $3^{\prime}, 4^{\prime}$-dihydrodiol-FAA peak area was not altered significantly, indicating that this dihydrodiol is not generated by simple chemical hydrolysis of the corresponding parent epoxide, but could be derived from an enzymatic hydrolysis. 


\section{Involvement of microsomal mouse epoxide hydrolase in the formation of $3^{\prime}, 4^{\prime}$-dihydrodiol-FAA}

To study the possible involvement of mouse epoxide hydrolase in the formation of the $3^{\prime}, 4^{\prime}$-dihydrodiol-FAA, we used elaidamide, a specific epoxide hydrolase inhibitor. In absence of elaidamide, all the FAA metabolites were formed, as presented in Figure 4-A. The first metabolite peak at Rt of 4.1 min was the $3^{\prime}, 4^{\prime}$-dihydrodiol-FAA. In presence of elaidamide (2 to $10 \mu \mathrm{M}$ ), the $3^{\prime}, 4^{\prime}$-dihydrodiol-FAA peak was reduced significantly (Figure 4-B) and the decrease was found to be concentration dependent of the epoxide hydrolase inhibitor as shown in Figure 4-C.

\section{Effect of FAA treatment on the expression of the principal Cyp enzymes in mice}

Because some flavonoids have been reported to modulate the expression of several enzymes, we next explored the effects of an in vivo treatment of FAA in mice on the expression of the principal hepatic Cyps using quantitative RT-PCR. For comparison purposes, the following standard inducers were also included in these experiments: phenobarbital, $\beta$-naphthoflavone, 3-methylcholanthrene, dexamethasone and aroclor 1254. The results are presented in Table 3 along with those of FAA after one or three in vivo treatments.

As expected, phenobarbital significantly induced the expression of Cyps 2b10, 2d9 and 3a11, by a factor of 3.2-, 2.5- and 1.6-fold, respectively (Table 3). Also as expected, $\beta$-naphthoflavone, 3-methylcholanthrene and aroclor were all potent inducers of several Cyps of the family 1 (Cyp1a1, 1a2, 1b1) (Table 3). Dexamethasone could also induce the following Cyps: Cyp1a1 (24-fold), 1a2 (4-fold), 1b1 (3.1-fold), 2 b10 (1.7-fold), 2d9 (18-fold) and 3a11 (3.6-fold).

Concerning the FAA, one treatment (180 mg/kg i.p.) unexpectedly led to a marked reduction of Cyp 1a1, 1a2 and $1 \mathrm{~b} 1$ transcripts (Table 3). However, after 3 FAA treatments, the following Cyps were significantly induced: Cyp1a2 (1.9-fold), 2e1 (2.1-fold), 2b10 (3.2-fold), 2d9 (2.3-fold), 3a11 (2.2-fold) (Table 3).

\section{DISCUSSION}

Although the metabolism of FAA has been hypothesized to be involved in its mechanism of anticancer activity in mice [11;12], the enzymes involved in FAA metabolism are presently unknown. The purpose of the present work was therefore to identify the principal phase I enzymes involved in FAA metabolism in vitro. In addition, because several flavonoids have been reported to be involved in the modulation of the expression of CYP enzymes [26], we were also interested to evaluate the possible effect of FAA treatment on the expression of the main Cyps expressed in mouse liver.

The principal FAA metabolites formed in vitro using aroclor-induced mouse microsomes consisted of one dihydrodiol $\left(3^{\prime}, 4^{\prime}\right.$ -dihydrodiol-FAA), three monohydroxylated metabolites (3'-OH-FAA, 4'-OH-FAA, 6-OH-FAA), and two epoxides (5,6-epoxy-FAA, 3',4' -epoxy-FAA). Of these metabolites, the two epoxides 5,6-epoxy-FAA and $3^{\prime}, 4^{\prime}$-epoxy-FAA were the predominant ones representing $36 \%$ and $27 \%$ of the total metabolites area, respectively.

Using Cyp-specific inhibitors, we have shown that the production of several FAA metabolites could be significantly reduced, thus providing novel information concerning the Cyp families and sub-families that are mostly involved in the formation of these metabolites. A summary of the principal mouse Cyps involved in FAA metabolism is presented in Figure 5. It can be noted that for the cycle A oxidation, 5,6-epoxidation was best afforded by Cyps 1a2, 1b1, 2b9, 2c39, 2c29, and 2e1, whereas for the 6-hydroxylation, Cyps 1b1 and $2 c 29$ were the most effective. For cycle B epoxidation ( $3^{\prime}, 4^{\prime}$-epoxy-FAA), Cyp 2b9/2c39 and 3a11 were the principal Cyps involved. For the formation of 4'-OH-FAA, Cyps 1a2, 1b1, 2b9 and 2e1 were the most effective.

Because monohydroxylation of phenols can also be generated through epoxide intermediates [42;43], we also evaluated the indirect production of the three monohydroxylated metabolites via an intermediate epoxide using $\mathrm{N}$-acetyl cysteine as an epoxide scavenger. In presence of NAC, the 4'-OH-FAA, the 3'-OH-FAA and the 6-OH-FAA, were significantly reduced, indicating that a significant percentage of these hydroxylated metabolites were indeed derived from the non enzymatic isomerization of their corresponding epoxides. The involvement of epoxide hydrolase in the formation of the $3^{\prime}, 4^{\prime}$-dihydrodiol-FAA was also confirmed using elaidamide, a specific inhibitor of this enzyme [30].

We were next interested to assess the influence of FAA on the expression of the principal hepatic Cyps after an in vivo administration in the mouse, because the expression of these enzymes can indeed be influenced by flavonoids [26]. Using quantitative RT-PCR, FAA was surprisingly found to have a dual effect, i.e., the repression of some Cyps after only one treatment, and the induction of other Cyps after three treatments. Concerning the repression of the expression of Cyps of the 1a subfamily after one in vivo treatment, this rather unexpected result may be due to the fact that some flavonoids may act as ligand of the aryl hydrocarbon receptor (AhR) at low concentrations and repress the transcription of the Cypla gene [44-46]. For the Cyp1b subfamily no evident mechanism is presently available to explain its repression. 
The induction of Cyps 1a2, 2e1, 2b10, 2d9 and 3a11 after three in vivo FAA treatments was also interesting. High concentrations of flavonoids have been previously shown to function as AhR agonists and may therefore activate the transcription of the Cypla gene. Since FAA is an unsubstituted flavonoid, it is remarkable that similar unsubstituted flavonoids, e.g., flavone and alpha-naphthoflavone, were also found to induce CYPs 1A1, 1A2 and 2B1/2 [44;47]. For the other Cyp subfamilies (i.e., 2d, 2e and 3a), there is no published data that we are aware of, concerning the induction of these Cyps by flavonoids.

In conclusion, we have found that several mouse Cyps are involved in the formation of FAA phase I metabolites. The two main metabolites formed in vitro were the 5,6-epoxy-FAA and the 3',4'-epoxy-FAA which were mainly formed by Cyps 1a2, 1b1, 2b9, 2c39, $2 \mathrm{c} 29$, and 2e1, for the former, and Cyps 2b9, 2c39, $3 \mathrm{a} 11$ for the latter. The formation of $3^{\prime}$-OH-FAA and 4'-OH-FAA were mainly derived from the $3^{\prime}, 4^{\prime}$-epoxy-FAA, whereas 6-OH-FAA was mainly formed directly $(60 \%)$ by Cyps $1 \mathrm{~b} 1$ and $2 \mathrm{c} 29$. After an in vivo administration of FAA in mice, the expression of Cyps 1a1, 1a2 and $1 \mathrm{~b} 1$ were repressed after one treatment, whereas three treatments led to an induction of Cyps 1a2, 2e1, 2b10, 2d9 and 3a11.

The enzymes identified in FAA metabolism, as well as their in vivo induction could probably play a role in the remarkable anticancer activity of FAA observed in mice. Although only phase I enzymes were studied in the present work, the involvement of other enzymes, particularly phase II enzymes, could also play a role in FAA anticancer activity because some flavonoids have recently been reported to exert their antiproliferative activity through sulfate conjugation [48].

\title{
Acknowledgements:
}

We thank Dr Christophe Morisseau for synthesizing and providing us with elaidamide, a specific epoxide hydrolase inhibitor. Supported by the Institut National de la Santé et de la Recherche Médicale (Inserm), the Centre National de la Recherche Scientifique (CNRS), and the Institut National du Cancer (INCa, Boulogne Billancourt, France).

\author{
Abbreviations used \\ Cyp : cytochrome P450 (mouse) \\ FAA : flavone-8-acetic acid \\ 3'-OH-FAA : 3'-hydroxy-FAA \\ 4'-OH-FAA : 4'-hydroxy-FAA \\ 6-OH-FAA : 6-hydroxy-FAA \\ NAC : N-acetylcysteine \\ RP-HPLC : reversed-phase high-performance liquid chromatography \\ MS : mass spectrometry \\ MS/MS : mass fragmentation pattern of molecular ion \\ Rt : retention time
}

\section{References:}

- 1. Middleton E Jr , Kandaswami C , Theoharides TC. The effects of plant flavonoids on mammalian cells: implications for inflammation, heart disease, and cancer . Pharmacol Rev . $2000 ; 52:$ (4) 673 - 751

- 2. Lopez-Lazaro M. Flavonoids as anticancer agents: structure-activity relationship study . Curr Med Chem Anticancer Agents . 2002 ; 2 : (6 ) 691 - 714

- 3. Corbett TH , Bissery MC, Wozniak A, Plowman J, Polin L, Tapazoglou E, Dieckman J, Valeriote F . Activity of flavone acetic acid (NSC-347512) against solid tumors of mice . Investigational 3ew Drugs . $1986 ; 4$ : (3 ) 207 - 220

- 4. Plowman J, Narayanan VL, Dykes D, Szarvasi E, Briet P, Yoder OC, Paull KD . Flavone acetic acid: a novel agent with preclinical antitumor activity against colon adenocarcinoma 38 in mice. Cancer Treat Rep . $1986 ; 70:$ : (5) 631 - 635

- 5 . Bibby MC, Double JA, Loadman PM. Unique chemosensitivity of MAC 16 tumours to flavone acetic acid (LM975, NSC 347512 ) . Br J Cancer . 1988 ; 58 : (3 ) 341 344

- 6. Pratesi G, Manzotti C, Damia G, D'Incalci M . Response of chemically induced primary colon tumours of the mouse to flavone acetic acid (NSC 347 512) . Br J Cancer . $1988 ; 58:$ (2) $144-146$

- 7 . Giavazzi R, Garofalo A, Damia G, Garattini S, D'Incalci M . Response to flavone acetic acid (NSC 347512) of primary and metastatic human colorectal carcinoma xenografts. Br J Cancer . $1988 ; 57:$ : (3 ) 277 - 280

- 8. Pratesi G, Manzotti C, Tortoreto M, Audisio RA, Zunino F. Differential efficacy of flavone acetic against liver versus lung metastases in a human tumour xenograft . Br J Cancer . $1991 ; 63:$ (1 ) $71-74$

- 9 . de Forni M, Chabot GG, Armand JP, Gouyette A, Klink-Alak M, Recondo G. Phase I and pharmacology study of flavone acetic acid administered two or three times weekly without alkalinization. Cancer Chemother Pharmacol . 1995; 35 : (3) 219 - 224

- 10 . Kerr DJ, Maughan T, Newlands E, Rustin G, Bleehen NM, Lewis C, Kaye SB . Phase II trials of flavone acetic acid in advanced malignant melanoma and colorectal carcinoma. Br J Cancer. $1989 ; 60$ : (1 ) 104 - 106

- 11. Chabot GG, Bissery MC, Gouyette A. Flavone acetic acid (LM-975, NSC-347512) activation to cytotoxic species in vivo and in vitro . Cancer Chemother Pharmacol . $1989 ; 24:(5) 273-276$

- 12 . Capolongo LS, Balconi G, Ubezio P, Giavazzi R, Taraboletti G, Regonesi A, Yoder OC, D'Incalci M . Antiproliferative properties of flavone acetic acid (NSC 347512) (LM 975), a new anticancer agent. Eur J Cancer Clin Oncol . $1987 ; 23:$ (10 ) 1529 - 1535

- 13. Drewinko B , Yang LY. The activity of flavone acetic acid (NSC 347512) on human colon cancer cells in vitro . Invest 3 ew Drugs . 1986 ; 4 : (4) 289 - 293

- 14. Schroyens WA, Dodion PF, Sanders C, Loos M, Dethier NE, Delforge AR, Stryckmans PA, Kenis Y . In vitro chemosensitivity testing of flavone acetic acid (LM975, NSC 347512) and its diethylaminoethyl ester derivative (LM985, NSC 293015). Eur J Cancer Clin Oncol . 1987 ; 23 : (8) 1135 - 1139

- 15 . Hornung RL, Back TC, Zaharko DS , Urba WJ , Longo DL, Wiltrout RH . Augmentation of natural killer activity, induction of IFN and development tumor immunity during the successful treatment of established murine renal cancer using flavone acetic acid and IL-2 . J Immunol . $1988 ; 141$ : (10 ) 3671 - 3679 
- 16. Lindsay CK, Gomez DE, Thorgeirsson UP . Effect of flavone acetic acid on endothelial cell proliferation: evidence for antiangiogenic properties . Anticancer Res . 1996 ; $16:$ : (1) $425-431$

- 17 . Evelhoch JL, Bissery MC, Chabot GG, Simpson NE, McCoy CL, Heilbrun LK, Corbett TH . Flavone acetic acid (NSC 347512)-induced modulation of murine tumor physiology monitored by in vivo nuclear magnetic resonance spectroscopy. Cancer Res . 1988 ; 48 : (17) 4749 - 4755

- 18. Bibby MC, Double JA, Loadman PM, Duke CV . Reduction of tumor blood flow by flavone acetic acid: a possible component of therapy . J 3atl Cancer Inst . 1989 ; 81 : (3) $216-220$

- 19. Hill S, Williams KB, Denekamp J . Vascular collapse after flavone acetic acid: a possible mechanism of its anti-tumour action . Eur J Cancer Clin Oncol . 1989 ; 25 : (10 ) $1419-1424$

- 20 . Zwi LJ , Baguley BC, Gavin JB , Wilson WR . Blood flow failure as a major determinant in the antitumor action of flavone acetic acid . J 3atl Cancer Inst . 1989 ; 81 : ( 13 ) $1005-1013$

- 21. Bissery MC, Valeriote FA, Chabot GG, Crissman JD, Yost C, Corbett TH . Flavone acetic acid (NSC 347512)-induced DNA damage in Glasgow osteogenic sarcoma in vivo . Cancer Res . $1988 ; 48:$ (5 ) 1279 - 1285

- 22. Pham MH, Auzeil N, Regazzetti A, Dauzonne D, Dugay A, Menet M-C, Scherman D, Chabot GG . Identification of new flavone-8-acetic acid metabolites using mouse microsomes and comparison with human microsomes. Drug Metab Dispos . 2007 ; 35 : (11 ) 2023 - 2024

- 23. Nelson DR, Zeldin DC, Hoffman SM , Maltais LJ , Wain HM , Nebert DW . Comparison of cytochrome P450 (CYP) genes from the mouse and human genomes, including nomenclature recommendations for genes, pseudogenes and alternative-splice variants . Pharmacogenetics . $2004 ; 14:(1) 1$ - 18

- 24 . Bogaards JJ, Bertrand M, Jackson P, Oudshoorn MJ, Weaver RJ , van Bladeren PJ, Walther B . Determining the best animal model for human cytochrome P450 activities: a comparison of mouse, rat, rabbit, dog, micropig, monkey and man. Xenobiotica . $2000 ; 30:$ (12) 1131 - 1152

- 25 . Martignoni M, Groothuis GM, de KR. Species differences between mouse, rat, dog, monkey and human CYP-mediated drug metabolism, inhibition and induction . Expert Opin Drug Metab Toxicol . 2006 ; 2 : (6 ) 875 - 894

- 26. Hodek P, Trefil P, Stiborova M . Flavonoids-potent and versatile biologically active compounds interacting with cytochromes P450 . Chem Biol Interact . 2002 ; 139 : (1 ) $1-21$

- 27 . Dauzonne D, Demerseman P . A convenient synthesis of 3-chloro-3,4-dihydro-4-hydroxy-3-nitro-2-phenyl-2H-1-benzopyrans . Synthesis . 1990 ; (01 ) 66 - 70

- 28. Dauzonne D, Folleas B , Martinez L, Chabot GG . Synthesis and in vitro cytotoxicity of a series of 3-aminoflavones . Eur J Med Chem . 1997 ; 3271 - 82

- 29. Bauvois B , Puiffe ML, Bongui JB, Paillat S, Monneret C, Dauzonne D . Synthesis and biological evaluation of novel flavone-8-acetic acid derivatives as reversible inhibitors of aminopeptidase N/CD13. J Med Chem . $2003 ; 46$ : (18 ) 3900 - 3913

- 30 . Morisseau C, Newman JW, Dowdy DL, Goodrow MH, Hammock BD. Inhibition of microsomal epoxide hydrolases by ureas, amides, and amines . Chem Res Toxicol $2001 ; 14:$ : (4) $409-415$

- 31. Breinholt VM, Offord EA, Brouwer C, Nielsen SE, Brosen K, Friedberg T . In vitro investigation of cytochrome P450-mediated metabolism of dietary flavonoids . Food Chem Toxicol . $2002 ; 40:$ (5) $609-616$

- 32. Guengerich FP . Editor: Hayes AW . Microsomal enzymes involved in toxicology - Analysis and separation . Principles and methods of toxicology . New York Raven Press ; $1982 ; 609-634$

- 33. Shimada T, Yamazaki H, Foroozesh M, Hopkins NE, Alworth WL, Guengerich FP. Selectivity of polycyclic inhibitors for human cytochrome P450s 1A1, 1A2, and 1B1. Chem Res Toxicol . $1998 ; 11:$ (9) 1048 - 1056

- 34 . Harris JW, Rahman A, Kim BR, Guengerich FP, Collins JM . Metabolism of taxol by human hepatic microsomes and liver slices: participation of cytochrome P450 3A4 and an unknown P450 enzyme. Cancer Res . 1994 ; 54 : (15 ) 4026 - 4035

- 35. Guengerich FP, Kim DH, Iwasaki M . Role of human cytochrome P-450 IIE1 in the oxidation of many low molecular weight cancer suspects . Chem Res Toxicol . 1991 ; 4 : (2) $168-179$

- 36. Maurice M, Pichard L, Daujat M, Fabre I, Joyeux H, Domergue J, Maurel P . Effects of imidazole derivatives on cytochromes P450 from human hepatocytes in primary culture . FASEB J . 1992; $6:$ (2) $752-758$

- 37 . Bu HZ, Kang P, Deese AJ, Zhao P, Pool WF. Human in vitro glutathionyl and protein adducts of carbamazepine-10,11-epoxide, a stable and pharmacologically active metabolite of carbamazepine. Drug Metab Dispos . 2005 ; 33 : (12 ) 1920 - 1924

- 38. Pan J , Xiang Q, Ball S. Use of a novel real-time quantitative reverse transcription-polymerase chain reaction method to study the effects of cytokines on cytochrome P450 mRNA expression in mouse liver . Drug Metab Dispos . $2000 ; 28$ : (6 ) 709 - 713

- 39 . Martignoni M, De Kanter R, Grossi P, Saturno G, Barbaria E, Monshouwer M . An in vivo and in vitro comparison of CYP gene induction in mice using liver slices and quantitative RT-PCR. Toxicol In Vitro . 2006; 20 : (1 ) 125 - 131

- 40 . Rutledge RG . Sigmoidal curve-fitting redefines quantitative real-time PCR with the prospective of developing automated high-throughput applications . Flucleic Acids Res . $2004 ; 32:(22)$ e 178 -

- 41. Rhinn H, Scherman D, Escriou V. One-step quantification of single-stranded DNA in the presence of RNA using Oligreen in a real-time polymerase chain reaction thermocycler. Anal Biochem . $2008 ; 372:$ (1 ) $116-118$

- 42 . Guengerich FP. Cytochrome P450 oxidations in the generation of reactive electrophiles: epoxidation and related reactions . Arch Biochem Biophys . 2003 ; 409 : (1) 59 71

- 43. Vyas KP, Shibata T, Highet RJ, Yeh HJ , Thomas PE, Ryan DE, Levin W, Jerina DM . Metabolism of alpha-naphthoflavone and beta-naphthoflavone by rat liver microsomes and highly purified reconstituted cytochrome P-450 systems . J Biol Chem . 1983 ; 258 : (9) 5649 - 5659

- 44 . Reiners JJ Jr, Clift R, Mathieu P. Suppression of cell cycle progression by flavonoids: dependence on the aryl hydrocarbon receptor . Carcinogenesis . 1999 ; 20 : (8) $1561-1566$

- 45 . Gasiewicz TA, Kende AS, Rucci G, Whitney B, Willey JJ . Analysis of structural requirements for Ah receptor antagonist activity: ellipticines, flavones, and related compounds . Biochem Pharmacol . $1996 ; 52$ : (11) 1787 - 1803

- 46 . Lu YF, Santostefano M, Cunningham BD, Threadgill MD, Safe S. Substituted flavones as aryl hydrocarbon (Ah) receptor agonists and antagonists . Biochem Pharmacol . $1996 ; 51:$ (8) $1077-1087$

- 47 . Canivenc-Lavier MC, Bentejac M, Miller ML, Leclerc J , Siess MH, Latruffe N, Suschetet M . Differential effects of nonhydroxylated flavonoids as inducers of cytochrome P450 1A and 2B isozymes in rat liver. Toxicol Appl Pharmacol . 1996; $136:$ (2 ) 348 - 353

- 48. Meng LH, Shankavaram U, Chen C, Agama K, Fu HQ, Gonzalez FJ, Weinstein J , Pommier Y . Activation of aminoflavone (NSC 686288) by a sulfotransferase is required for the antiproliferative effect of the drug and for induction of histone Y-H2AX . Cancer Res . $2006 ; 66$ : (19) 9656 - 9664 
Figure 1

A) Structure of flavone-8-acetic acid (FAA) and its phase I metabolites formed in vitro with mouse microsomes. B) Representative HPLC-UV chromatogram of FAA and its metabolites.

A
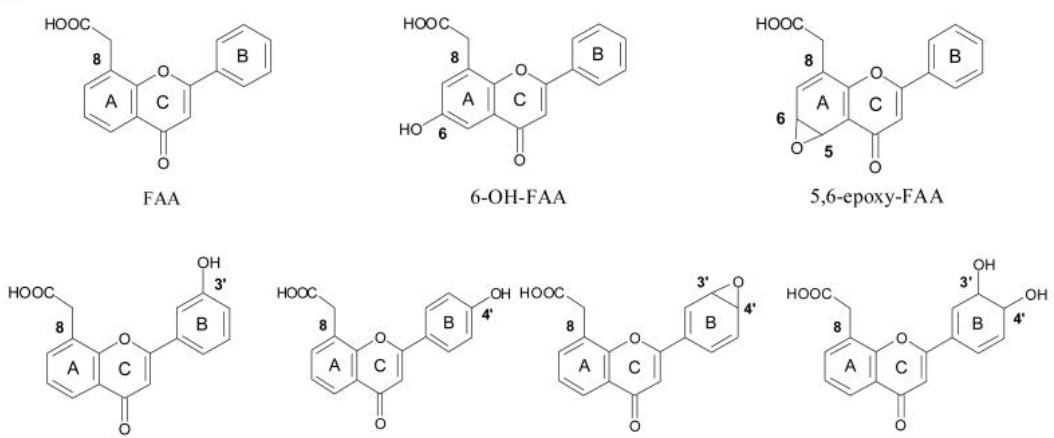

3'-OH-FAA

4'-OH-FAA

3',4'-epoxy-FAA

3',4'-dihydrodiol-FAA

B

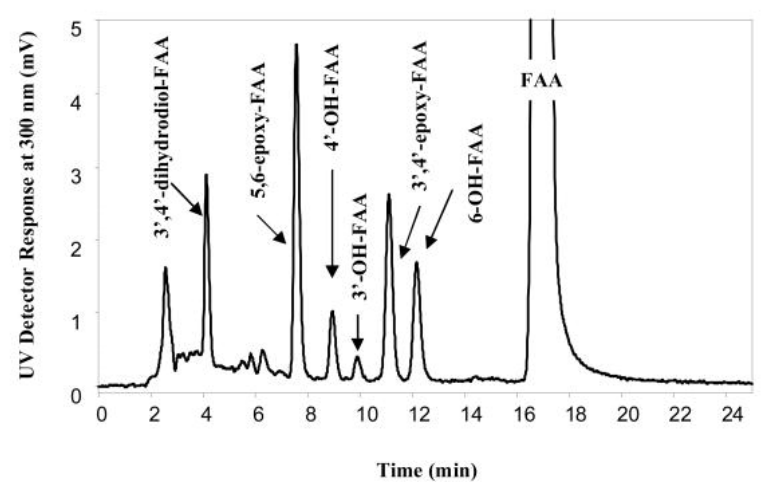

Figure 2

HPLC-UV chromatogram showing FAA metabolism in absence (A), or presence of the Cyp1a2 inhibitor furafylline at a final concentration of $50 \mu \mathrm{g} / \mathrm{ml}$ (B) .

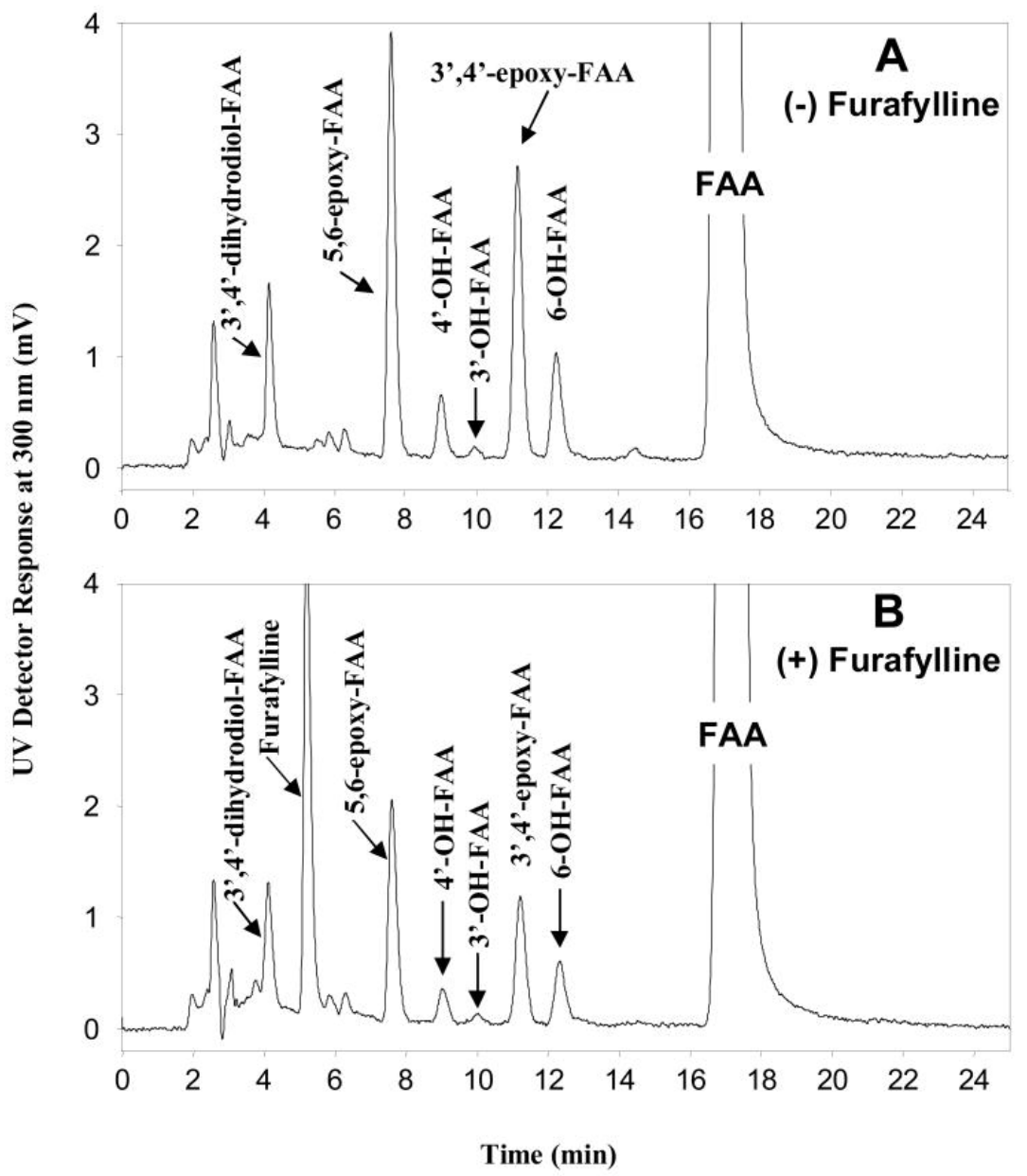




\section{Figure 3}

HPLC-UV chromatogram analysis (gradient elution) for the determination of direct or indirect hydroxylation using N-acetylcysteine (NAC), as an epoxide scavenger. A) chromatogram of FAA metabolism in absence of NAC. B) Chromatogram of FAA metabolism in presence of NAC at $7.5 \mathrm{mM}$. C) Reconstituted chromatogram at $\mathrm{m} / \mathrm{z}=460$ of FAA metabolites in presence of NAC at $7.5 \mathrm{mM}$. D) Reconstituted chromatogram at $\mathrm{m} / \mathrm{z}=460$ of FAA metabolism in absence of NAC.

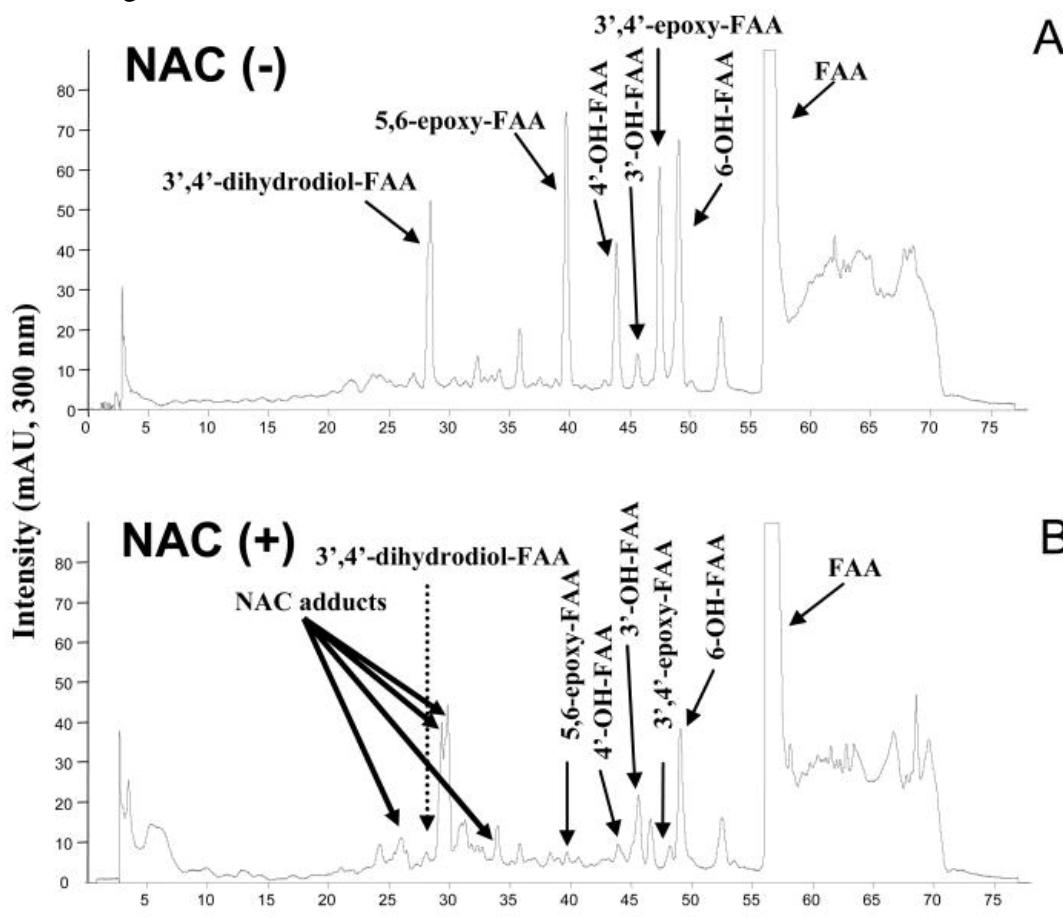

A

B

Time (min)

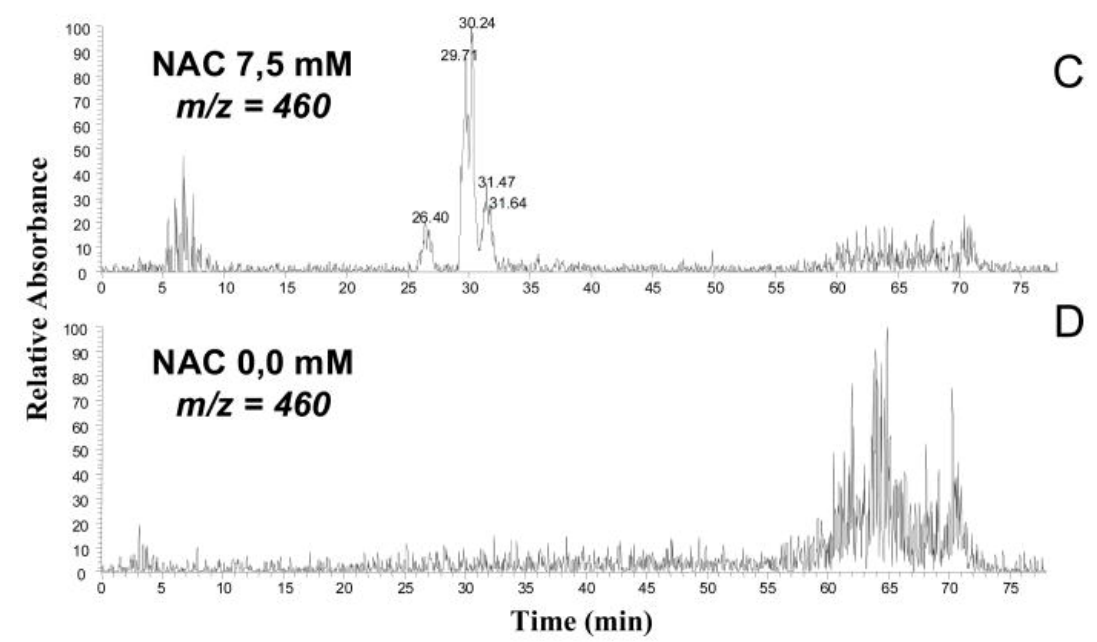




\section{Figure 4}

HPLC-UV chromatograms depicting the involvement of epoxide hydrolase in the production of the $3^{\prime}, 4^{\prime}$-dihydrodiol-FAA. A) FAA metabolism in absence of elaidamide, an epoxide hydrolase inhibitor. B) FAA metabolism in presence of elaidamide (10 $\mu$ M). C) Histogram showing the elaidamide concentration dependent decrease in the formation of the $3^{\prime}, 4^{\prime}$-dihydrodiol-FAA.
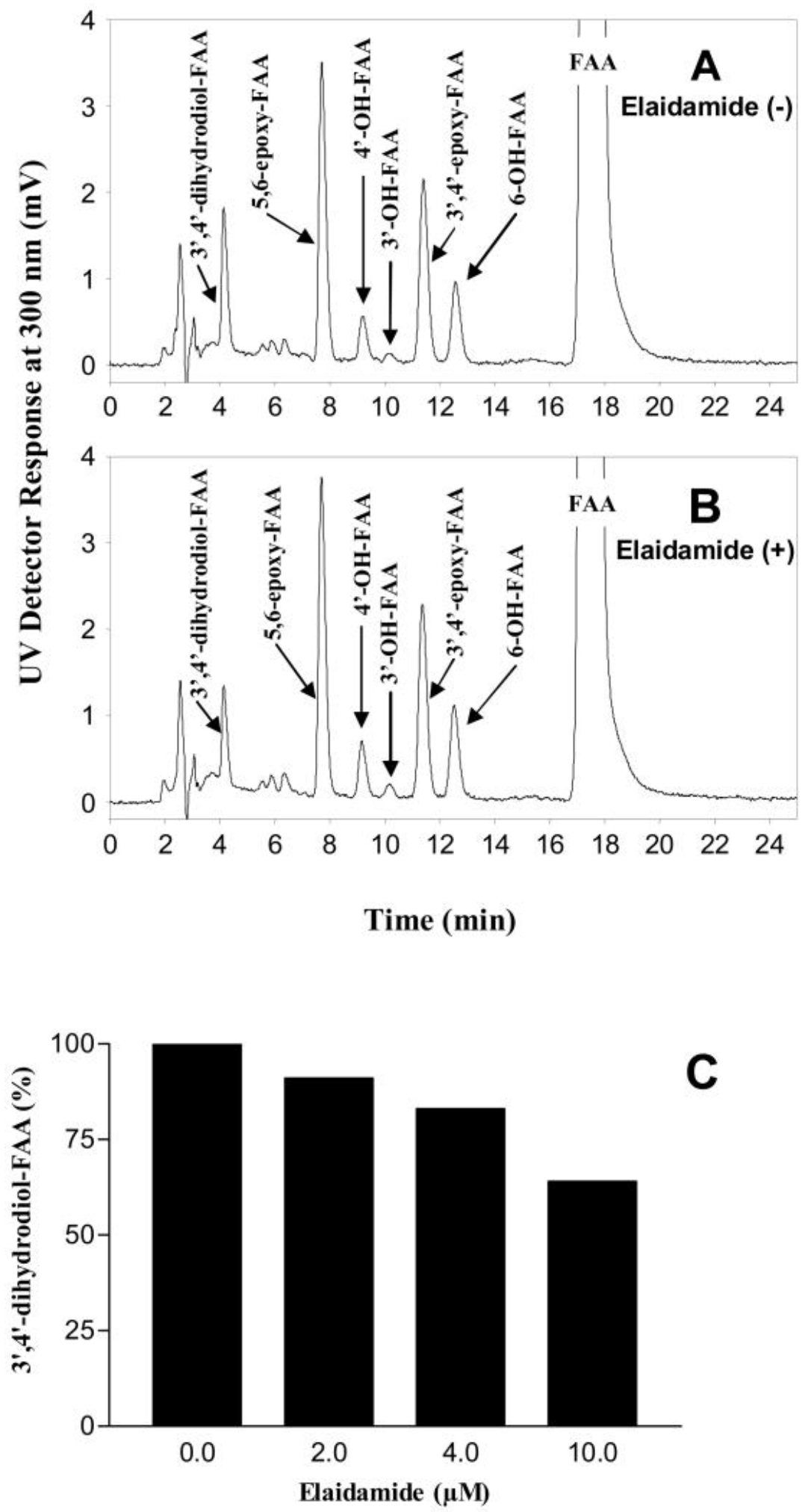
Figure 5

Schematic summary of proposed FAA phase I metabolic pathways using aroclor-induced mouse microsomes showing the principal enzymes involved.

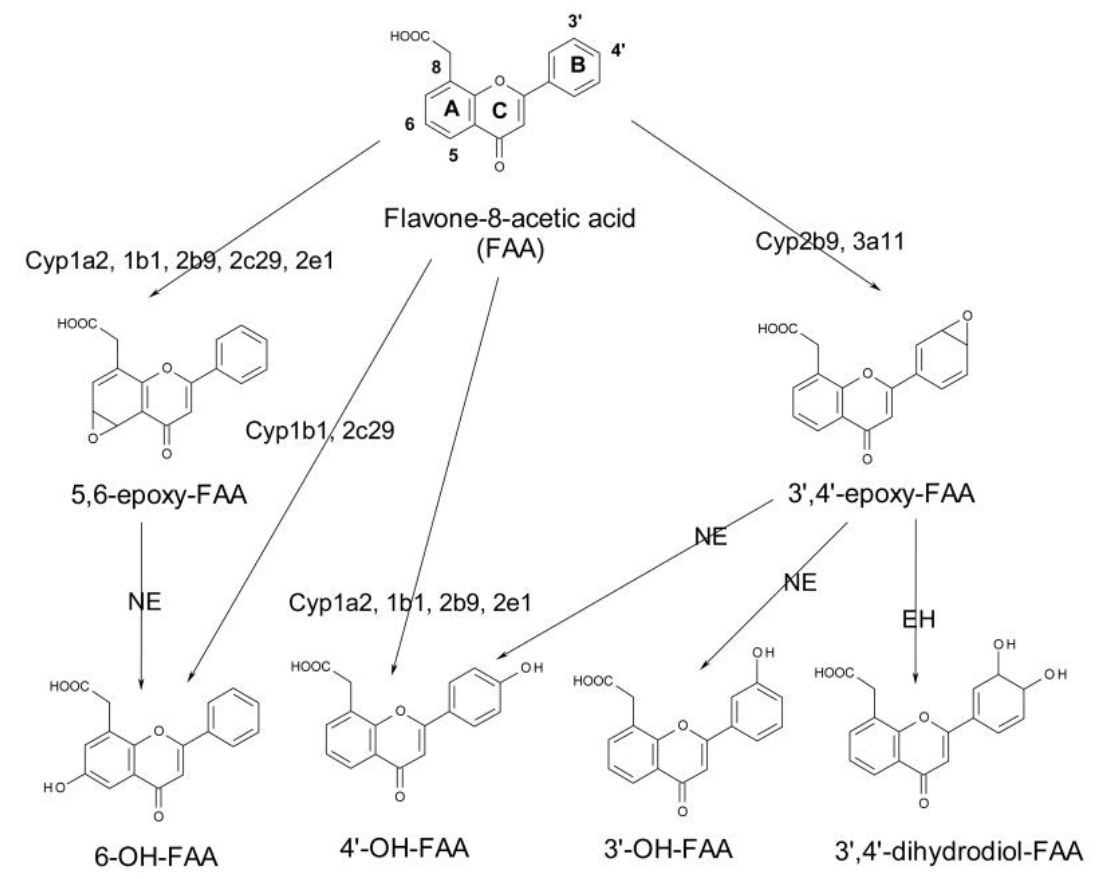


Table 1

Primers used for the determination of mouse cytochrome P450s (Cyp) mRNA

\begin{tabular}{|c|c|c|c|c|}
\hline Cyp gene & Forward primer & Reverse primer & PCR product (bp) & GenBank number \\
\hline$\overline{\text { Cyp1a1 }}$ & 867-GGGAGGTTACTGGCTCTGGA & 1077-TGGACATTGGCATTCTCGT & 220 & NM_009992 \\
\hline Cyp1a2 & 961-CCCGAGGAGAAGATTGTCAAC & 1102-CGATCCCTGCCAACCAC & 158 & NM_009993 \\
\hline Cyp1b1 & 1315-TGCCTGCCACTATTACGGA & 1440-GTCCСТCСCCACAАCCTG & 143 & NM_009994 \\
\hline Cyp2b10 & 937-GGCTTCCTGCTCATGCTC & 1020-CGGTCATCAAGGGTTGGT & 101 & NM_009999 \\
\hline Сур2d9 & 1173-CGCTTTGGGGACATTGTT & 1257-GTTGGGGAGGAGGATCGT & 102 & NM_010006 \\
\hline Cyp2e1 & 786-CACTGGACATCAACTGCCC & 947-ATGAGAATCAGGAGCCCATA & 181 & NM_021282 \\
\hline Cyp3a11 & 328-GTCACAGACCCAGAGACGAT & 553-TTTGCCTTCTGCCTCAAGTA & 245 & NM_007818 \\
\hline
\end{tabular}


Table 2

Determination of mouse cytochrome P450s (Cyps) involved in the metabolism of FAA in vitro using Cyp specific inhibitorsa

\begin{tabular}{|c|c|c|c|c|c|c|}
\hline \multirow{2}{*}{ Inhibitor (Cyp inhibited) } & \multirow[t]{2}{*}{ Inhibitor Conc. $(\mu \mathrm{M})$} & \multicolumn{5}{|l|}{ Percent inhibition } \\
\hline & & 3',4'-di-hydrodiol-FAA & 5,6-epoxy-FAA & 4'-OH-FAA & 3', 4'-epoxy -FAA & 6-OH-FAA \\
\hline \multirow{4}{*}{ Furafylline (Cyp1a2) } & 5 & $-3 \pm 5 b$ & $19 \pm 3$ & $7 \pm 4$ & $-2 \pm 5$ & $-3 \pm 8$ \\
\hline & 10 & $6 \pm 6$ & $34 \pm 13$ & $29 \pm 10$ & $5 \pm 8$ & $19 \pm 12$ \\
\hline & 20 & $14 \pm 8$ & $42 \pm 6$ & $35 \pm 3$ & $27 \pm 5$ & $28 \pm 5$ \\
\hline & 50 & $36 \pm 1$ & $57 \pm 2$ & $52 \pm 3$ & $54 \pm 3$ & $52 \pm 6$ \\
\hline \multirow{3}{*}{ a-naphthoflavone (Cyp1b1) } & 5 & $10 \pm 1$ & $5 \pm 5$ & $5 \pm 4$ & $-29 \pm 6$ & $16 \pm 1$ \\
\hline & 10 & $50 \pm 1$ & $21 \pm 9$ & $32 \pm 20$ & $-18 \pm 11$ & $53 \pm 1$ \\
\hline & 20 & $89 \pm 3$ & $76 \pm 14$ & $70 \pm 15$ & $40 \pm 16$ & $84 \pm 4$ \\
\hline \multirow{4}{*}{ Tranylcypromine (Сур2b9, Сур2c39) } & 25 & $4 \pm 10$ & $23 \pm 3$ & $13 \pm 4$ & $10 \pm 1$ & $-17 \pm 31$ \\
\hline & 50 & $45 \pm 8$ & $52 \pm 2$ & $44 \pm 5$ & $42 \pm 4$ & $10 \pm 34$ \\
\hline & 75 & $68 \pm 1$ & $68 \pm 2$ & $57 \pm 2$ & $59 \pm 2$ & $29 \pm 33$ \\
\hline & 100 & $75 \pm 3$ & $74 \pm 3$ & $64 \pm 7$ & $64 \pm 3$ & $37 \pm 32$ \\
\hline \multirow{3}{*}{ Quercetin (Сyp2c29) } & 10 & $-21 \pm 7$ & $26 \pm 6$ & NDc & ND & $25 \pm 12$ \\
\hline & 20 & $13 \pm 7$ & $48 \pm 11$ & ND & ND & $53 \pm 8$ \\
\hline & 30 & $52 \pm 7$ & $73 \pm 6$ & ND & ND & $85 \pm 4$ \\
\hline \multirow{4}{*}{ Quinidine (Сур2d9) } & 10 & $1 \pm 4$ & $17 \pm 13$ & $-7 \pm 13$ & $-5 \pm 9$ & $-23 \pm 11$ \\
\hline & 50 & $7 \pm 4$ & $20 \pm 4$ & $5 \pm 4$ & $-7 \pm 1$ & $-26 \pm 3$ \\
\hline & 100 & $15 \pm 8$ & $27 \pm 1$ & $13 \pm 7$ & $-16 \pm 5$ & $-17 \pm 3$ \\
\hline & 200 & $39 \pm 2$ & $35 \pm 5$ & $24 \pm 5$ & $-13 \pm 0$ & $5 \pm 10$ \\
\hline \multirow{4}{*}{ Diethyldithiocarbamate (Сyp2e1) } & 50 & $-61 \pm 12$ & $1 \pm 5$ & $17 \pm 7$ & $-66 \pm 26$ & $-3 \pm 4$ \\
\hline & 100 & $-53 \pm 8$ & $24 \pm 5$ & $31 \pm 7$ & $-67 \pm 16$ & $4 \pm 10$ \\
\hline & 200 & $-29 \pm 20$ & $49 \pm 6$ & $54 \pm 2$ & $-62 \pm 46$ & $34 \pm 5$ \\
\hline & 300 & $28 \pm 15$ & $75 \pm 4$ & $71 \pm 9$ & $11 \pm 17$ & $62 \pm 2$ \\
\hline \multirow{5}{*}{ Ketoconazole (Cyp3a11) } & 2 & $75 \pm 3$ & $17 \pm 8$ & $-40 \pm 6$ & $-82 \pm 7$ & $-16 \pm 2$ \\
\hline & 4 & $88 \pm 1$ & $16 \pm 1$ & $-20 \pm 20$ & $-101 \pm 10$ & $-9 \pm 11$ \\
\hline & 10 & $94 \pm 1$ & $41 \pm 5$ & $-32 \pm 31$ & $-62 \pm 9$ & $2 \pm 13$ \\
\hline & 20 & $96 \pm 1$ & $61 \pm 4$ & $25 \pm 6$ & $0 \pm 7$ & $35 \pm 7$ \\
\hline & 40 & $97 \pm 1$ & $85 \pm 1$ & $62 \pm 11$ & $59 \pm 2$ & $78 \pm 1$ \\
\hline
\end{tabular}

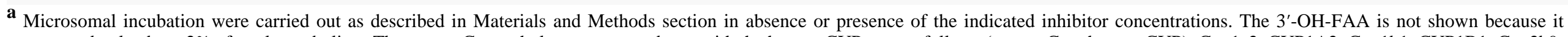

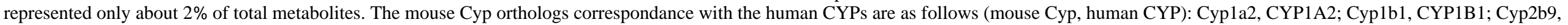
CYP2B6; Cyp2c39, CYP2C19; Cyp2d9, CYP2D6; Cyp2e1, CYP2E1; Cyp3a11, CYP3A4.

b Mean \pm SEM of 3 independent determination.

$\mathbf{c}_{\mathrm{ND}}$, not determined, because of inhibitor peak interference with these metabolites. Bold characters indicate intermediate inhibitor concentrations. 
Table 3

Quantitative RT-PCR determination of the principal cytochrome P450s (Cyp) induced by standard inducers and flavone-8-acetic acid (FAA)a

\begin{tabular}{|c|c|c|c|c|c|c|c|}
\hline Inducer & 1a1b & $1 \mathrm{a} 2$ & $1 \mathrm{~b} 1$ & $2 \mathrm{e} 1$ & $2 \mathrm{~b} 10$ & $2 d 9$ & $3 a 11$ \\
\hline Phenobarbital & $0.07 \mathrm{c} \pm 0.04$ & $0.75 \pm 0.1$ & $0.2 \pm 0.09$ & $1 \pm 0.2$ & $3.2 \pm 0.7$ & $2.5 \pm 0.4$ & $1.6 \pm 0.1$ \\
\hline$\beta$-naphthoflavone & $450 \pm 330$ & $30 \pm 9$ & $28 \pm 8$ & $1.1 \pm 0.05$ & $1.6 \pm 0.2$ & $2.4 \pm 0.5$ & $1.2 \pm 0.3$ \\
\hline 3-methylcholanthrene & $11000 \pm 2900$ & $180 \pm 17$ & $680 \pm 120$ & $1.5 \pm 0.1$ & $2.4 \pm 0.7$ & $2.9 \pm 0.4$ & $1.5 \pm 0.4$ \\
\hline Dexamethasone & $24 \pm 16$ & $4 \pm 2$ & $3.1 \pm 1.7$ & $0.78 \pm 0.02$ & $1.7 \pm 0.2$ & $18 \pm 3.9$ & $3.6 \pm 1.0$ \\
\hline Aroclor 1254 & $7800 \pm 2900$ & $200 \pm 39$ & $370 \pm 89$ & $0.4 \pm 0.1$ & $8.4 \pm 1.4$ & $6.0 \pm 1.4$ & $5.5 \pm 1.6$ \\
\hline FAA 1 treatment & $0.003 \pm 0.001$ & $0.08 \pm 0.01$ & $0.1 \pm 0.01$ & $0.6 \pm 0.1$ & $0.5 \pm 0.08$ & $0.5 \pm 0.1$ & $0.7 \pm 0.1$ \\
\hline FAA 3 treatments & $0.6 \pm 0.3$ & $1.9 \pm 1.1$ & $1.1 \pm 0.3$ & $2.1 \pm 0.5$ & $3.2 \pm 1.5$ & $2.3 \pm 0.7$ & $2.2 \pm 0.4$ \\
\hline
\end{tabular}

a Levels of Cyp transcripts were determined by quantitative RT-PCR as described in the Materials and Methods section.

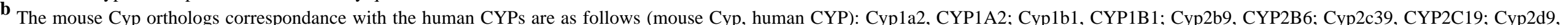

CYP2D6; Cyp2e1, CYP2E1; Cyp3a11, CYP3A4.

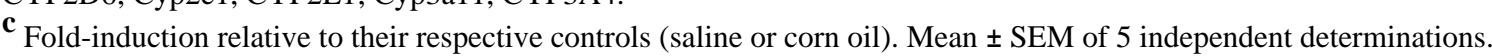

